\title{
Upper eyelid ectropion repair
}

\author{
Valentín Huerva, Diego Castanera
}

Department of Ophthalmology, University Hospital Arnau de Vilanova, Lleida, Spain

\section{Correspondence to}

Dr Valentín Huerva,

vhuerva@gmail.com

Accepted 3 September 2017
CrossMark

\section{To cite: Huerva $V_{\text {, }}$}

Castanera D. BMJ Case

Rep Published Online First:

[please include Day Month

Year]. doi:10.1136/bcr-2017-

221982

\section{DESCRIPTION}

A 75-year-old man presented with a constant, not repositioned left upper eyelid ectropion (figure 1). The patient had suffered several episodes of infectious keratitis due to eyeball exposure. The lower eyelid presented also an ectropion due to hyperlaxity. Severely injected and hypertrophied superior tarsal conjunctiva was observed. The cornea was tarnished with loss of brightness due to poor lubrication by exposition (figure 1). The patient had no history of previous surgery, traumatic event, obstructive sleep apnoea (OSA) syndrome or multiple endocrine neoplasia. He underwent an upper lid lateral full thickness semilunar wedge resection of $15 \mathrm{~mm}$ and levator muscle aponeurosis reattachment through the eyelid crease (figures 2 and 3). A lateral tarsal sling was performed in lower eyelid. Epithelial hyperplasia with parakeratosis was informed in the histological study (figure 4). Cosmetic and functional results were rapidly obtained. No recurrence was noted over an 8-month follow-up (figure 5).

Upper eyelid ectropion is a rare condition. Few cases have been reported. ${ }^{1}$ Spontaneous upper eyelid eversion has been described associated to floppy eyelid syndrome. Many of these have a severe OSA and usually occurs during night sleep. ${ }^{23}$ However, this patient has no OSA. Additionally, this case presents inferior lower eyelid ectropion due to the hyperlaxity. Surgical correction of lower eyelid ectropion is well established. On the contrary, the correction of superior eyelid ectropion constitutes a challenge. In the first place, the rarity of the process makes it difficult for the general ophthalmologist to solve this problem. Second, because of the great horizontal laxity. Unlike ectropion of the lower eyelid that can be improved with lateral tensioning, a shortening is necessary through a full thickness

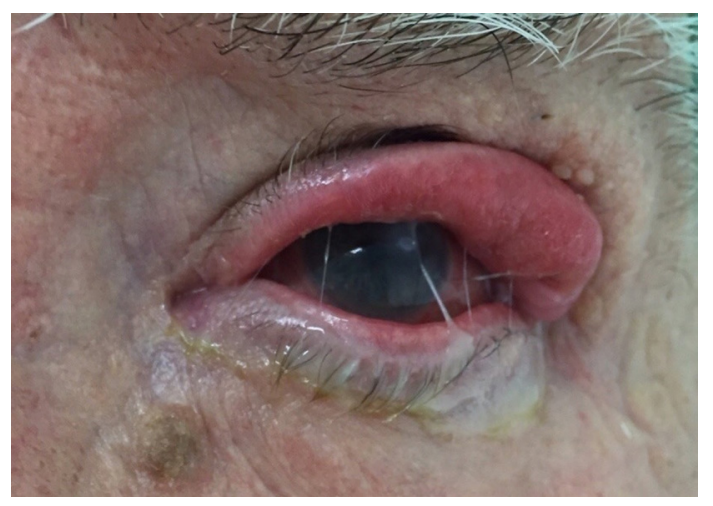

Figure 1 Constant upper left eyelid ectropion. Secretions and corneal leucoma due to previous infectious keratitis. Loss of corneal brightness due to poor lubrication by exposition.

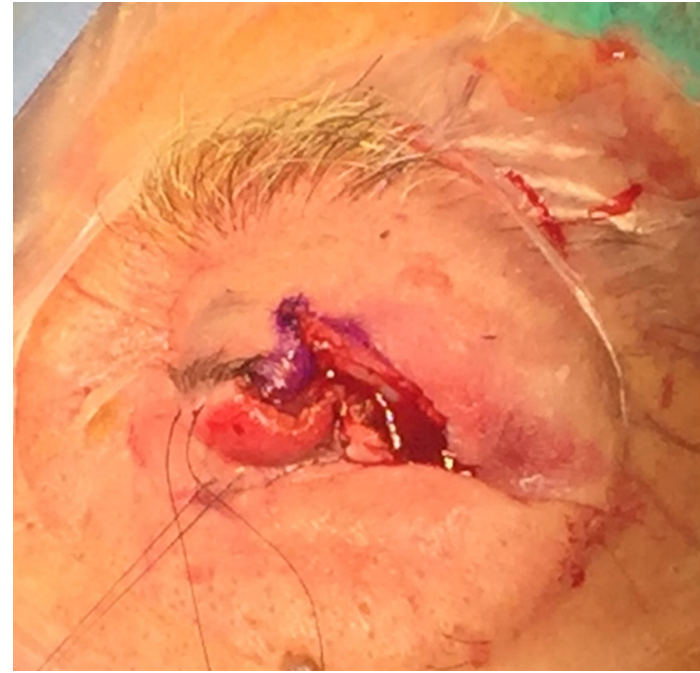

Figure 2 Lateral full thickness semilunar wedge resection of $15 \mathrm{~mm}$ in upper eyelid.

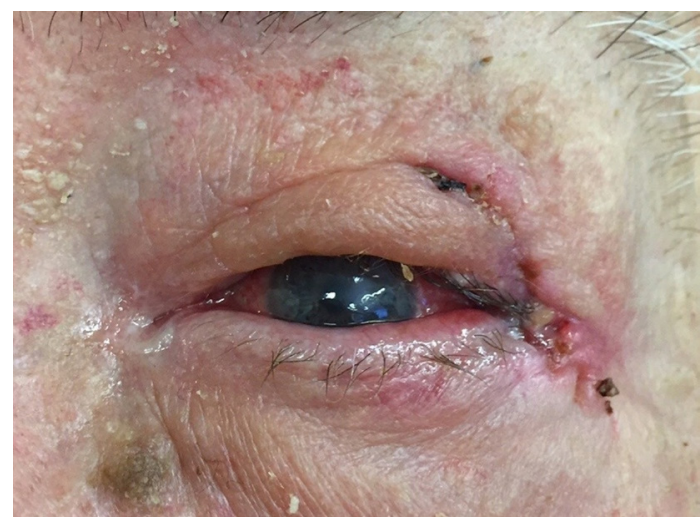

Figure 3 Aspect after suture removal (10 days of the surgery). Eyelid oedema. The eyelid crease is reformed.

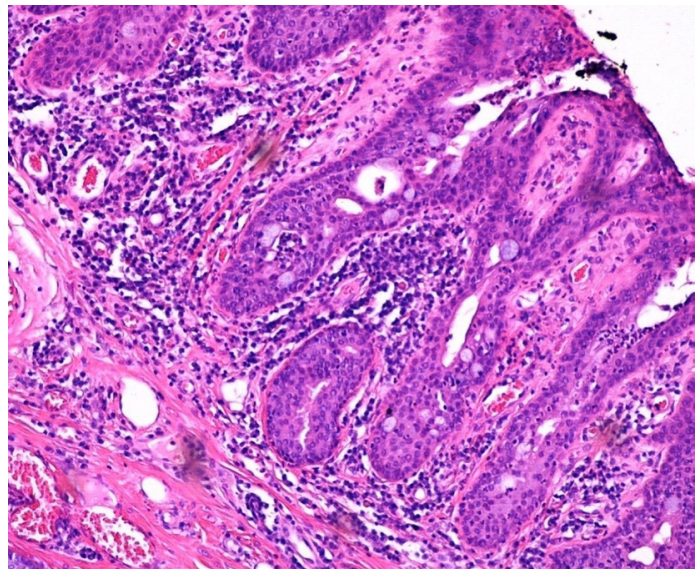

Figure 4 Epithelial hyperplasia with parakeratosis (H\&E 10x). 


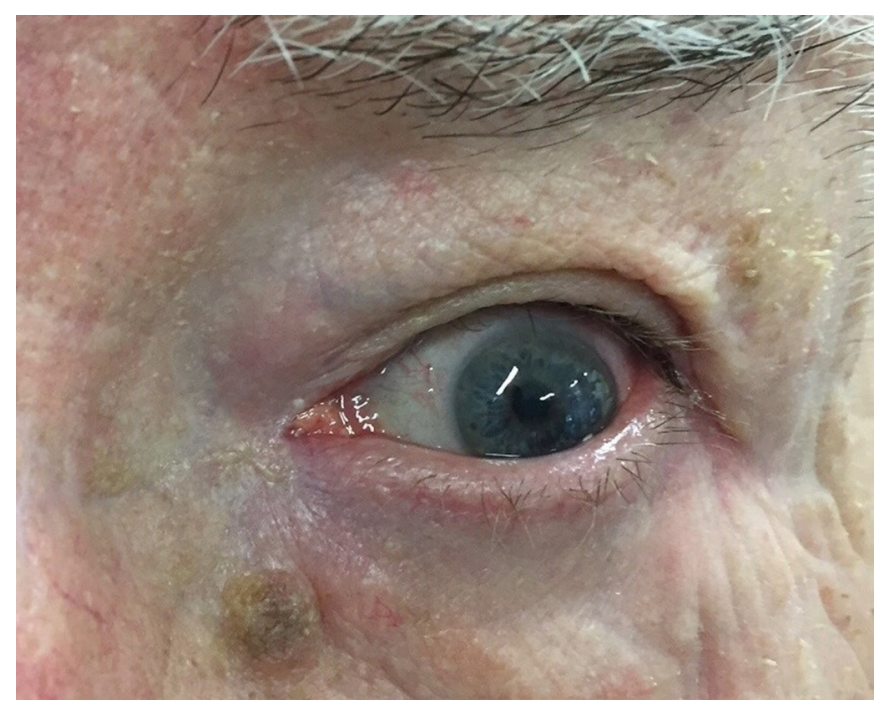

Figure 5 No ectropion and evident eyelid crease. Absence of secretions and corneal brightness recovery.

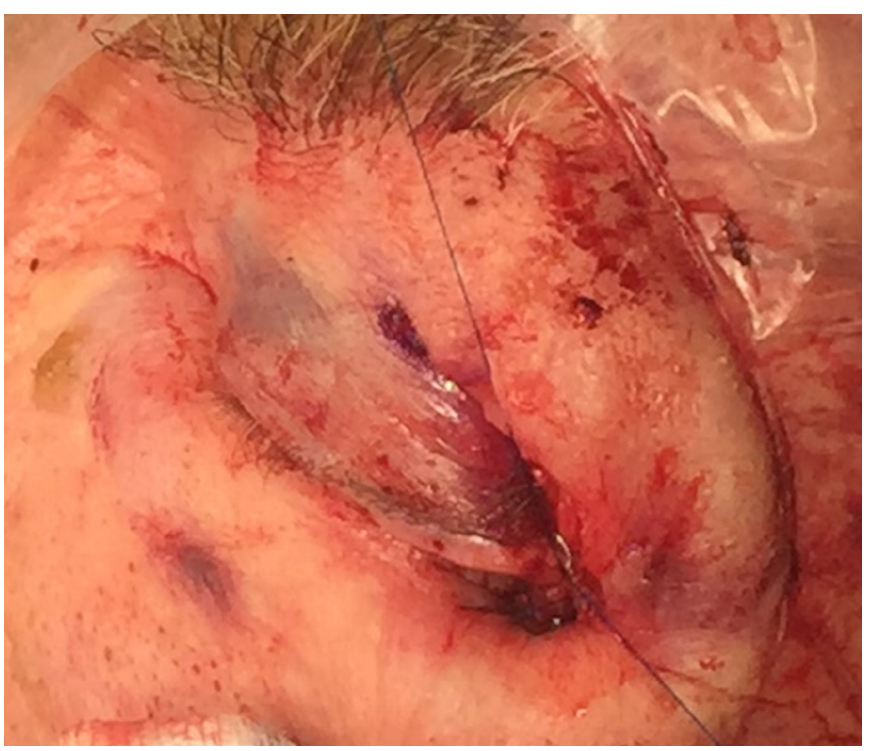

Figure 6 Appearance when joining the two edges of semilunar resection.

wedge resection. In addition to improve the eyelid dynamics, it should be necessary to examine or repair the condition of the levator muscle aponeurosis. A full thickness pentagonal wedge resection is usually described. ${ }^{1}$ We perform a shortening in a semilunar form instead of a pentagonal form as usually described in other reports. ${ }^{1}$ A semilunar resection was easier and more cosmetic when joining the two ends (figure 6). On the other hand, the upper end of the semilunar wedge is continued by the eyelid crease to perform the incision and completion of the reinsertion of the aponeurosis to the tarsus. With a wide full thickness resection you may obtain a horizontal tightening of the upper eyelid. However, a reinsertion or repair of the elevator aponeurosis is necessary to obtain the inversion and apposition of the upper eyelid with the eyeball at the same time.

\section{Learning points}

- Upper eyelid ectropion is not usual and it may occur without a known associated systemic disease.

- A lateral semilunar full thickness wide wedge resection and an elevator muscle aponeurosis reattachment can correct this type of ectropion.

- A semilunar resection may result easier and more cosmetic when joining the two ends. Unlike the pentagonal resection, the closure of the two edges is simpler, being able to get covered in the palpebral fold resulting more aesthetic.

Contributors VH: conception and design, acquisition of data, analysis and interpretation of data; drafting the article and revising it critically for important intellectual content; final approval of the version to be published. DC: acquisition of data, analysis and interpretation of data; revising the article critically for important intellectual content; final approval of the version to be published.

\section{Competing interests None declared.}

Patient consent Detail has been removed from this case description/these case descriptions to ensure anonymity. The editors and reviewers have seen the detailed information available and are satisfied that the information backs up the case the authors are making.

Provenance and peer review Not commissioned; externally peer reviewed. (c) BMJ Publishing Group Ltd (unless otherwise stated in the text of the article) 2017. All rights reserved. No commercial use is permitted unless otherwise expressly granted.

\section{REFERENCES}

1 Leibovitch I, Davis G, Selva D, et al. Non-cicatricial upper eyelid ectropion. Br J Ophthalmol 2005;89:1226-7.

2 Muniesa MJ, Huerva V, Sánchez-de-la-Torre M, et al. The relationship between floppy eyelid syndrome and obstructive sleep apnoea. Br J Ophthalmol 2013;97:1387-90.

3 Huerva V, Muniesa MJ, Ascaso FJ. Floppy eyelid syndrome in obstructive sleep apnea syndrome. Sleep Med 2014;15:724-5.

Copyright 2017 BMJ Publishing Group. All rights reserved. For permission to reuse any of this content visit

http://group.bmj.com/group/rights-licensing/permissions.

BMJ Case Report Fellows may re-use this article for personal use and teaching without any further permission.

Become a Fellow of BMJ Case Reports today and you can:

- Submit as many cases as you like

- Enjoy fast sympathetic peer review and rapid publication of accepted articles

- Access all the published articles

- Re-use any of the published material for personal use and teaching without further permission

For information on Institutional Fellowships contact consortiasales@bmjgroup.com

Visit casereports.bmj.com for more articles like this and to become a Fellow 